\title{
Levels of neuropeptide $Y$ in synovial fluid relate to pain in patients with knee osteoarthritis
}

\author{
Lei Wang ${ }^{1,2^{*}}$, Li Zhang ${ }^{3 \dagger}$, Haobo Pan ${ }^{1}$, Songlin Peng ${ }^{4}$, Minmin Lv ${ }^{1}$ and William Weijia Lu ${ }^{1,5^{*}}$
}

\begin{abstract}
Background: The precise etiology of knee osteoarthritis (KOA) pain remains highly controversial and there is no known effective treatment. Due to the known and suggested effects of neuropeptide Y (NPY) on pain, we have sought to investigate the relationship between the concentration of NPY in synovial fluid of knee, pain of KOA, and structural severity of KOA.

Methods: One hundred KOA patients and twenty healthy participants (control group) were recruited. The pain and the radiographic grade of KOA were assessed separately by Hideo Watanabe's pain score and Tomihisa Koshino's scoring system. Synovial fluid of knee from all participants was collected with arthrocentesis. Radioimmunoassay was used to examine the concentration of NPY in synovial fluid of knee.

Results: Concentrations of NPY in synovial fluid were significantly higher in KOA patients $(124.7 \pm 33.4 \mathrm{pg} / \mathrm{mL})$ compared with controls $(64.8 \pm 26.3 \mathrm{pg} / \mathrm{mL})(p=0.0297)$. According to Hideo Watanabe's pain score, $100 \mathrm{KOA}$ patients were divided into 5 subgroups: no pain $(n=12)$, mild pain $(n=25)$, moderate pain $(n=37)$, strong pain $(n=19)$ and severe pain $(n=7)$. Within the KOA group, significantly higher concentrations of NPY were found in each subgroup as pain intensified (no pain $81.4 \pm 11.7 \mathrm{pg} / \mathrm{mL}$, mild pain $99.1 \pm 23.2 \mathrm{pg} / \mathrm{mL}$, moderate pain $119.9 \pm 31.5 \mathrm{pg} / \mathrm{mL}$, strong pain $171.2 \pm 37.3 \mathrm{pg} / \mathrm{mL}$ and severe pain $197.3 \pm 41.9 \mathrm{pg} / \mathrm{mL}$ ). Meanwhile, according to Tomihisa Koshino's scoring system, $100 \mathrm{KOA}$ patients were divided into 3 subgroups: early stage $(n=30)$, middle stage $(n=53)$, advanced stage $(n=17)$. Concentrations of NPY in middle and advanced stage groups of KOA patients were significant higher than early stage group of KOA patients (early stage $96.4 \pm 27.1 \mathrm{pg} / \mathrm{mL}$, middle stage $153.3 \pm 16.9 \mathrm{pg} / \mathrm{mL}$, advanced stage $149.5 \pm 36.7 \mathrm{pg} / \mathrm{mL})(p=0.0163, p=0.0352)$. Concentrations of NPY in advanced stage group of KOA patients has no significant difference compare with middle stage group of KOA patients $(p=0.2175)$.
\end{abstract}

Conclusions: This study demonstrated the presence and variation of concentrations of NPY in the KOA joint fluid, suggesting a role for NPY as a putative regulator of pain transmission and perception in KOA pain.

Keywords: Pathogenesis, Arthrophlogosis, Synovia, Radioimmunoassay, Regulator

\section{Background}

Knee osteoarthritis (KOA) is a chronic degenerative joint disorder that affects a large proportion of the population, particularly in elderly people [1-6]. Epidemiological studies have revealed that over $70 \%$ of people aged 65 years or older suffer from OA with the knee joint being most commonly affected [7]. KOA patients' major clinical manifestation is chronic pain that typically

\footnotetext{
*Correspondence: wldzzs@163.com; jw.lv@siat.ac.cn

${ }^{\dagger}$ Equal contributors

${ }^{1}$ Center for Human Tissues and Organs Degeneration, Shenzhen Institute of Advanced Technology, Chinese Academy of Science, 1068 Xueyuan Avenue, 518055 Shenzhen, China

Full list of author information is available at the end of the article
}

worsens as a result of weight bearing, activity or movement of the affected joint [8]. Synovial inflammation raised intra-osseous pressure and mechanical stresses on intra-articular and peri-articular ligaments and tendons [9-11] are potential contributors to the chronic pain encountered. However, the precise aetiology of KOA pain remains highly controversial, which limits the progress in developing effective treatments for KOA pain [12].

Neuropeptide Y (NPY), a 36 amino acid peptide, is one of the most widely distributed neuropeptides in the nervous system [13,14]. It has diverse and complex biological functions, such as capacity to influence 
cardiovascular performance, food intake and pain processing [15-17]. In addition, pathophysiological role of NPY in infection and inflammation, as well as in autoimmunity, has been suggested $[18,19]$. The up-regulation of NPY in the dorsal root ganglia and spinal cord has been shown in various models of inflammatory and neuropathic pain [20-23] and around blood vessels in the capsule of the joint [24-26]. NPY and its Y1 and Y2 receptors are located at key pain signaling centers throughout the nervous systems [27-32]. Previous work also suggested that joint pain results from the activation of primary afferent nerve fibers by neuropeptides at the joint [33-35]. Due to the known and suggested important effects of NPY on pain, we hypothesized that NPY may be involved in the pathogenesis of KOA pain. Therefore, the aim of this study was to assess the relationship between concentrations of NPY in the synovial fluid of knee, KOA pain, and structural severity of KOA.

\section{Methods}

\section{Ethics statement}

This study is in accordance with the ethical principles of the Declaration of Helsinki and was approved by the Local Research Ethics Committee (Research Ethics Committee of People's Hospital of Hangzhou, Nanjing Medical University), and the trial number 023-01 from Research Ethics Committee of People's Hospital of Hangzhou, Nanjing Medical University.

All participants provided informed, written consent.

\section{Patients}

This one year study was conducted in People's Hospital of Hangzhou, Nanjing Medical University from January 2009 to January 2010.

One hundred KOA patients were recruited from the department of orthopedic surgery in People's Hospital of Hangzhou, fulfilling the American College of Rheumatology clinical criteria for the diagnosis of KOA [36]. In case of bilateral KOA, the more serious pain and/or edema and/ or deformed side (determined by the patient's subjective judgment) was assessed. Exclusion criteria included knee joint trauma ever in their lives (periarticular fracture, meniscectomy, etc.), other arthritis (gout, rheumatoid arthritis, purulent arthritis, etc.), metabolic bone diseases (osteoporosis, Paget's disease, osteopetrosis, etc.), malignancy, bone tumor (multiple myeloma, etc.), primary or secondary hyperparathyroidism, inflammatory arthropathy and any knee surgery during the last 6 months. In addition, patients were excluded if any anti-inflammatory drugs (oral NSAID, etc.), odynolysis and/or corticotherapy were used within the past 4 weeks.

Twenty healthy participants between 35 and 65 years of age without any diseases judged by the physician were recruited from the People's Hospital of Hangzhou as the control groups.

\section{KOA pain assessment}

Pain was assessed by the physician based on the patient's medical history according to Hideo Watanabe's knee scoring system-related pain score [37]. Patients with KOA were divided into 5 groups: no pain group, mild pain group, moderate pain group, strong pain group and severe pain group (Table 1).

\section{KOA radiographic grade}

Full-extension posterior-anterior radiographs (X-ray) of the knees were obtained and assessed by the physician. The degree of radiographic KOA in individual joints was graded (0 to 5$)$ by the study investigator using the Tomihisa Koshino's scoring system [38]. Grade 1 was considered early stage, grade $2-3$ was middle stage and grade $4-5$ was advanced stage (Table 2).

\section{Arthrocentesis \& joint fluid sampling}

All participants were in a supine position on a stretcher. The same entry site was demarcated with a skin-marking pen. The skin was prepared with povidone-iodine. A sterile drape was placed around the site. Then the region was anesthetized by placing a wheal of lidocaine, using a small (25-gauge) needle. Intermittently the plunger was pulled back during the injection of the anesthetic to exclude intravascular placement.

An 18-gauge needle was used directly behind the patella into the synovial cavity with the lateral approach. Upon insertion into the articular cavity, $3 \mathrm{~mL}$ of $0.9 \%$ saline was injected slowly into the joint and after $20 \mathrm{~s} 3 \mathrm{~mL}$ of turbidappearing fluid was aspirated and immediately centrifuged (2000 rev/min, $10 \mathrm{~min}$ ) at $4^{\circ} \mathrm{C}$ and stored at $-70^{\circ} \mathrm{C}$ until analyzed. Synovial fluid from healthy individuals were collected, frozen, and stored in the same way as the KOA patients.

\section{Table 1 Hideo Watanabe's knee scoring system-related} pain score

\begin{tabular}{|c|c|}
\hline Group & Standard \\
\hline No pain group & $\begin{array}{l}\text { Occasionally feeling fatigue or heaviness, } \\
\text { but no pain at any time }\end{array}$ \\
\hline Mild pain group & $\begin{array}{c}\text { Pain at starting time of various activities or } \\
\text { occasionally during long-distance walking, } \\
\text { but no pain at rest }\end{array}$ \\
\hline Moderate pain group & $\begin{array}{c}\text { Pain usually on walking, but pain gradually } \\
\text { subside after a brief rest }\end{array}$ \\
\hline Strong pain group & $\begin{array}{c}\text { Persistent pain on walking, but pain gradually } \\
\text { mitigates after a rest, usually associate with } \\
\text { spontaneous pain }\end{array}$ \\
\hline Severe pain group & $\begin{array}{c}\text { Persistent pain at any time, including walking } \\
\text { and rest }\end{array}$ \\
\hline
\end{tabular}


Table 2 Tomihisa Koshino's radiographic grading for osteoarthritic knees in a weightbearing position ${ }^{\mathrm{a}}$

\begin{tabular}{lll}
\hline Stage & Grade & Standing $\mathbf{x}$-ray \\
\hline Early stage & 0 & Normal \\
Middle stage & 2 & Bone sclerosis or osteophyte formation \\
& 2 & Narrowing of joint space $(\leq 3 \mathrm{~mm})$ \\
Advanced stage & 4 & Obliteration of joint space or subluxation \\
& 5 & Defect of tibial plateau $(<5 \mathrm{~mm})$ \\
& 5 & Defect of tibial plateau $(\geq 5 \mathrm{~mm})$ \\
\hline
\end{tabular}

${ }^{\mathrm{a}} \mathrm{An}$ anteroposterior and weight-bearing radiograph taken in a standing position was used for grading.

"Subluxation" indicates the condition in which the medial edge of the medial tibial plateau shows a lateral shift by more than $5 \mathrm{~mm}$ against the medial edge of articular surface of the medial femoral condyle without including osteophyte.

\section{NPY in synovial fluid}

Radio-immunoassay was performed to determine concentrations of NPY in KOA synovial fluid. Concentrations of NPY in joint fluid was determined by commercially available radioimmunoassay kits (Iodine $\left[{ }^{125} \mathrm{I}\right]$ Neuropeptide Radioimmunoassay kit, Institute of RIA, Chinese PLA General Hospital, China) in accordance with the standard protocols included in the kits. The sensitivity of the radioimmunoassay kit was $<33 \mathrm{pg} / \mathrm{mL}$.

\section{Statistical analysis}

All analyses were performed using SPSS version 13.0. Data presented as mean \pm SD. Bartlett's method was performed first to identify the homogeneity of variances. Group $t$-test was used to compare the mean of concentrations of NPY in synovial fluid of KOA Group with Healthy control group. Dunnett- $t$ test was used to compare the mean of concentrations of NPY in synovial fluid of each subgroup of KOA Group with Healthy control group. In addition, the Student-Newman-Keuls (SNK) test was used to compare the mean of concentrations of NPY in synovial fluid of each KOA subgroup. A linear regression was used to assess the relationship between concentrations of NPY in synovial fluid and the pain of
KOA patients. A $p$ value less than 0.05 was considered to be statistically significant.

\section{Results}

\section{Participant demographics}

In total, $100 \mathrm{KOA}$ patients and 20 healthy controls participated in this study. The mean age of the KOA patients was $56 \pm 6.9$ years and $48 \pm 8.1$ years for the healthy controls, which was not significantly different $(p=0.347)$. The gender distribution between the two groups was similar with $39 \%$ of the KOA patients and $50 \%$ of healthy controls being male $(p=0.3609)$.

\section{KOA pain and NPY concentrations}

As previously stated the KOA patients $(n=100)$ were divided into 5 groups according to Hideo Watanabe's pain score: no pain group $(n=12)$, mild pain group $(n=25)$, moderate pain group $(n=37)$, strong pain group $(n=19)$ and severe pain group $(n=7)$ (Figures 1 and 2$)$.

In all tested KOA groups, there was a positive correlation between concentrations of NPY and the level of pain. Concentrations of NPY were significantly higher in KOA patients $(124.7 \pm 33.4 \mathrm{pg} / \mathrm{mL})$ than in healthy participants $(64.8 \pm 26.3 \mathrm{pg} / \mathrm{mL})(p=0.0297)$. Within KOA subgroups, significantly higher concentrations of NPY were found in each subgroup as pain increased (no pain group $81.4 \pm 11.7 \mathrm{pg} / \mathrm{mL}$, mild pain group $99.1 \pm$ $23.2 \mathrm{pg} / \mathrm{mL}$, moderate pain group $119.9 \pm 31.5 \mathrm{pg} / \mathrm{mL}$, strong pain group $171.2 \pm 37.3 \mathrm{pg} / \mathrm{mL}$ and severe pain group $197.3 \pm 41.9 \mathrm{pg} / \mathrm{mL})$.

\section{$\mathrm{KOA}$ radiographic grade and NPY concentrations}

As previously stated, $100 \mathrm{KOA}$ patients were divided into 3 stage groups according to Tomihisa Koshino's scoring system: early $(n=30)$, middle $(n=53)$ and advanced $(n=17)$ (Figure 3).

Concentrations of NPY were significantly higher in the KOA patients $(124.7 \pm 33.4 \mathrm{pg} / \mathrm{mL})$ compared to the healthy controls $(64.8 \pm 26.3 \mathrm{pg} / \mathrm{mL})(p=0.0297)$.

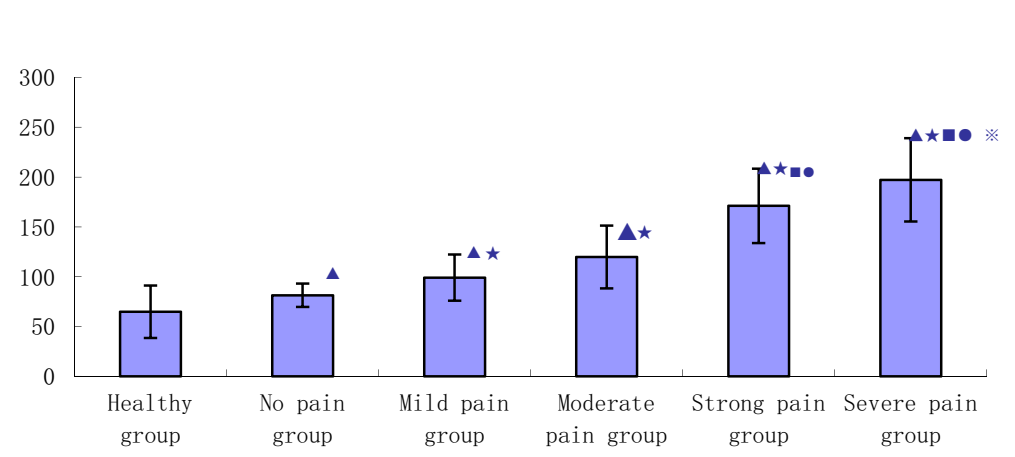

口NPY $(\mathrm{pg} / \mathrm{ml})$

Figure 1 Comparison of pain and NPY concentrations of KOA patients with healthy participants. ( $p<0.05: \mathbf{\Delta}$ vs. Healthy control group; Intragroup KOA ${ }^{\star}$ vs. No pain group, "vs. Mild pain group, ${ }^{\bullet}$ vs. Moderate pain group, * vs. Strong pain group). 


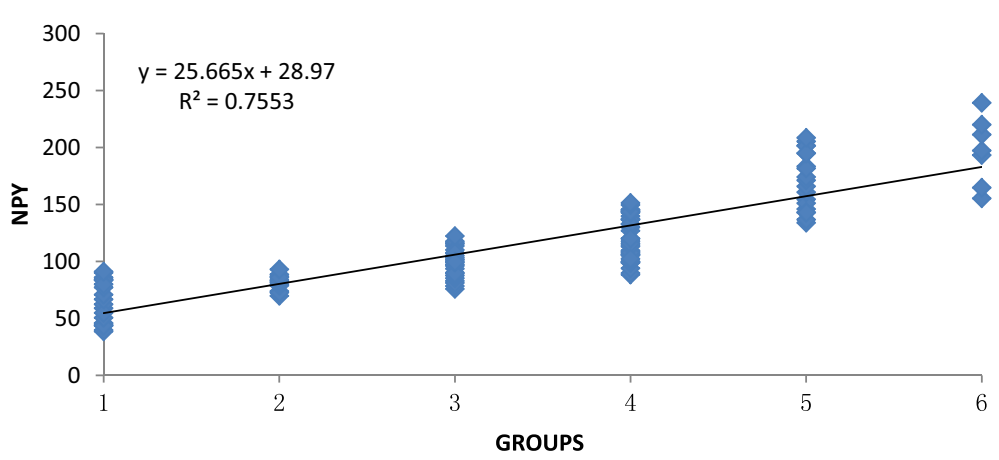

Figure 2 The correlation between synovial fluid NPY concentration and pain of KOA patients. ( 1 = Healthy control group, $2=$ No pain group, 3 = Mild pain group, 4 = Moderate pain group, $5=$ Strong pain group, $6=$ Severe pain group).

Concentrations of NPY in the middle and advanced staged patients $(153.3 \pm 16.9 \mathrm{pg} / \mathrm{mL}, 149.5 \pm 36.7 \mathrm{pg} / \mathrm{mL})$ were significantly higher compared to the early staged patients $(96.4 \pm 27.1 \mathrm{pg} / \mathrm{mL}) \quad(p=0.0163, p=0.0352)$. Concentrations of NPY in the advanced staged patients were not significantly different compared to the middle staged patients $(p=0.2175)$.

\section{Discussion}

Despite the widespread prevalence of KOA in the adult population, very little is known about the source of KOA pain, which may be initiated by chemical mediators in KOA joints [39]. Due to the role of NPY in pain [20-23,27-32], we sought to study the effect of varying concentrations of NPY in KOA joint fluid and its association with the pain, and structural severity of KOA. To our knowledge, this is the first study specifically designed to evaluate the relationship between concentrations of NPY, KOA pain, and structural severity of KOA.

Our primary finding was that concentrations of NPY were significantly higher in KOA patients compared to healthy controls. The results of our study were in agreement with the available clinical literature, which has also found significantly higher concentrations of NPY in the synovial fluid of patients with arthritis of the knee (crystal induced arthritis, chronic polyarthritis, post-infectious arthritis, rheumatoid arthritis), compared to control patients with non-inflammatory joint disorders (lateral meniscus injury, medial meniscus injury, cruciate ligament injury), admitted for arthroscopy [40,41].

With an increase in pain based on each KOA subgroups we found significantly higher concentrations of NPY. This result was similar to literatures that found that pain gradually developed from the initial mild pain into a long period of severe pain during the pathological process of KOA [9-12]. This indicates that levels of NPY are related to the joint pain in patients with KOA.

Concentrations of NPY in synovial fluid of middle and advanced KOA stages were significantly higher than early KOA stage. But concentrations of NPY in synovial fluid of advanced stage of KOA patients have no significant difference to compare with middle stage of KOA patients. These results contradict the notion that NPY has significant relevance to joint pain in patients with $\mathrm{KOA}$, and significantly higher concentrations of NPY may lead to a significant increase in pain. It suggests a lack of agreement between X-rays evidence of KOA and patients' report of pain at that site base on the result of our studies, which are the first study specifically designed to evaluate the relationship between NPY and KOA pain. Meanwhile, the orthopedic community has been plagued for years by this discordance. Many researchers [42-46]

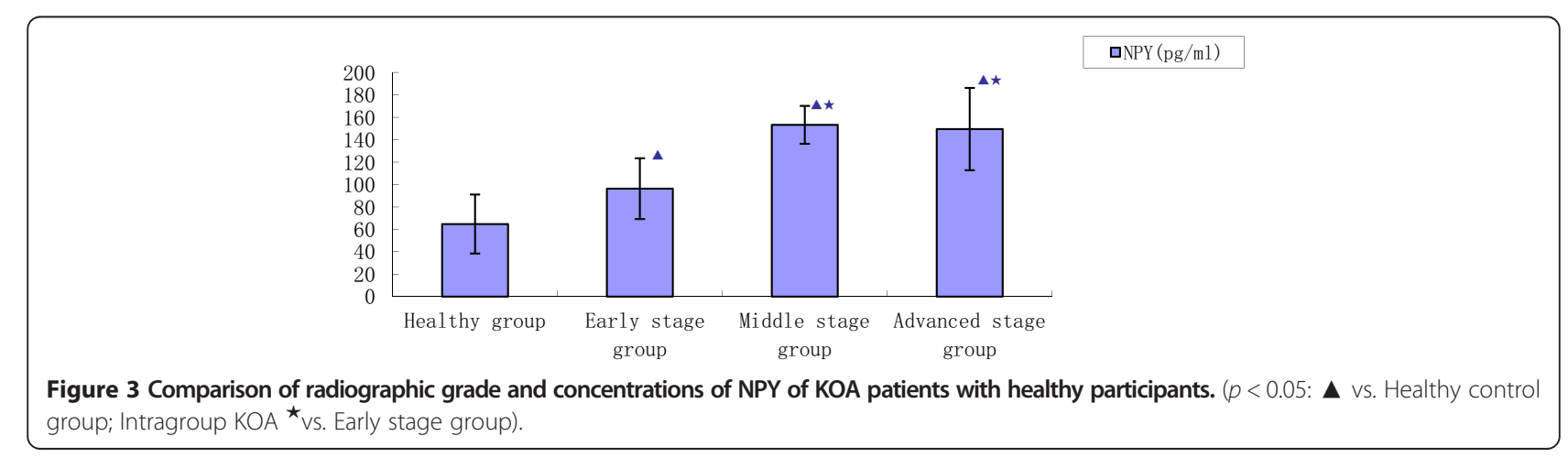


have found evidence for a substantial discordance between pain and observed radiographic evidence of KOA. In a 2008 systematic review of population studies, Bedson and Croft quantitatively described the problem for KOA: "In those with radiographic KOA the proportion with pain ranged from $15 \%$ to $81 \%$ " [47]. The discordance between pain and radiographic KOA points to the need for further investigation of this phenomenon. And, the different subscales of classifications for grade of KOA may be one of the causes. The obliteration of joint space, which is considered middle stage in this study, is quite advanced KOA and according to the Kellgren-Lawrence scoring system would represent end-stage KOA (grade 4). This may help explain why no differences were found between middle and advanced KOA groups.

Studies have shown that during arthritis, pro-infla mmatory mediators are released into the joint [48] which sensitize the joint afferent neurons. This can cause previous innocuous physicochemical stimuli to activate these neurons which will lead to the sensation of joint pain $[49,50]$. One important family of agents known to be involved in the peripheral sensitization of joint afferents is the inflammatory neuropeptides, which include NPY [30-32,51]. NPY (belonging to the pancreatic polypeptide family) was first isolated from pig brain by Tatemoto [24]. NPY is produced together with noradrenaline in certain sympathetic nerve fibers [25] and has a strong and longstanding vasoconstrictive effect on both arterial and venous vessels. In the rat, this neuropeptide was found around blood vessels in the capsule of the joint, but not in the disc or cartilaginous joint surfaces [26]. This potent neuromodulator is stored in the terminal branches of $\mathrm{A} \delta$ and $C$ fibers where it's release into the joint lowers the activation threshold of nociceptive nerve endings, which is likely to contribute to chronic, sensitized pain responses [52]. Based on the current study, the presence and variation of NPY in KOA joint fluid strongly points to a role as a regulator of pain transmission and perception in KOA pain. Possible mechanisms by which NPY can modulate pain processing. NPY can lower membrane $\mathrm{Ca}^{2+}$ conductance in dorsal root ganglion neurons and inhibits substance $\mathrm{P}$ released from the central terminals of the primary afferent fibers $[14,53,54]$. Furthermore, the observation that peripheral inflammation increases both NPY and its Y1 and Y2 receptor synthesis in the spinal dorsal horn reinforces the concept that spinal NPY participates in the processing of nociception [12]. Noradrenergic neurons of the locus coeruleus and A1 noradrenergic cell groups also constitute a major system concerned with the modulation of nociception [55] and NPY is co-localized with noradrenaline in a sub-population of the neurons $[25,56,57]$. In the locus coeruleus, NPY depresses the spontaneous firing rate of these neurons and the hyperpolarizing effect of $\alpha_{2}$-agonists through stimulation of its $\mathrm{Y} 2$ receptor subtype [58].

\section{Study limitations}

This study is limited by a small sample size and the different sub-scales of classifications for pain and grade of KOA. In addition, the underlying molecular and cellular mechanisms of NPY in KOA pain remain poorly understood. Hopefully, future studies will provide answers to these questions.

\section{Conclusions}

This study demonstrated the concentrations of NPY between KOA patients and healthy controls. These results suggest a role for NPY as a putative regulator of pain transmission and perception of KOA pain. In addition, concentrations of NPY may reflect the pathological progressing and severity of KOA. The precise roles of NPY in the pathogenesis of KOA pain require further investigation. However, our results have contributed to a better understanding of the molecular processes underlying KOA pain and, in addition, foster the option of local therapeutic intervention targeting NPY. The understanding of the role of NPY in KOA pain is a prerequisite to developing such novel therapeutic options for the treatment of KOA pain and restoration of tissue function.

\section{Abbreviations}

KOA: Knee osteoarthritis; OA: Osteoarthritis; NPY: Neuropeptide Y;

NSAID: Non-steroidal anti-inflammatory drug; RIA: Radioimmunoassay;

SPSS: Statistical Product and Service Solutions; SNK test: Student-Newman-Keuls test.

\section{Competing interests}

The authors declare that they have no competing interest.

\section{Authors' contributions}

LW was the grant holder of the trial. This work was jointly conceived, planned, and written up by LW and WL. The analytic KOA pain assessment and $\mathrm{KOA}$ radiographic grade were performed by $\mathrm{HP}$ and $\mathrm{SP}$. LZ and ML using the Radio-immunoassay to identify the concentrations of NPY. All authors read and approved the final manuscript.

\section{Acknowledgments}

We thank Prof. Shenglin Ma (Department of Oncology, People's Hospital of Hangzhou, Nanjing Medical University, China), Prof. Liulong Zhu (Department of Orthopedic Surgery, People's Hospital of Hangzhou, Nanjing Medical University, China), Prof. Tomihisa Koshino (Department of Orthopedic Surgery, Yokohama City University school of medicine, Japan), Prof. Dick Heinegard (Department of Clinical Sciences, University of Lund, Sweden) and Prof. Hala Zreiqat (Tissue Engineering \& Biomaterials Research Unit, University of Sydney, Australia) for providing consultation.

This investigation was supported by grants from the National Nature Science Foundation of China $(81201384,81270967,81371989)$, the National Nature Science Foundation of Zhejiang Province (LQ12H06005) and New Science and Technology in Prevention and Treatment of Bone of ShenZhen (110811003586331), which had no involvement in the study design, collection, analysis and interpretation of data, writing of the manuscript or in the decision to submit the manuscript for publication.

\section{Author details}

${ }^{1}$ Center for Human Tissues and Organs Degeneration, Shenzhen Institute of Advanced Technology, Chinese Academy of Science, 1068 Xueyuan Avenue, 518055 Shenzhen, China. ²Department of Orthopedic Surgery, People's Hospital of Hangzhou, Nanjing Medical University, 261 Huansha Road, Hangzhou 310006, China. ${ }^{3}$ Institute of Biomedicine and Biotechnology, Shenzhen Institute of Advanced Technology, Chinese Academy of Science, 
1068 Xueyuan Avenue, Shenzhen 518055, China. ${ }^{4}$ Department of Orthopedic Surgery, People's Hospital of Shenzhen, Jinan University Second College of Medicine, 1017 Dongmen North Road, Shenzhen 518020, China. ${ }^{5}$ Department of Orthopaedics and Traumatology, Li Ka Shing Faculty of Medicine, The University of Hong Kong, Pokfulam, China.

Received: 15 January 2014 Accepted: 23 September 2014 Published: 27 September 2014

\section{References}

1. WHO: The burden of musculoskeletal conditions at the start of the new millennium. World Health Organ Tech Rep Ser 2003, 919:1-218.

2. Felson DT: The epidemiology osteoarthritis. In Osteoarthritis. Edited by Brandt KD, Doherty M, Lohmander LS. Oxford, England: Oxford University Press; 2003:9-16.

3. Le Pen C, Reygrobellet C, Gerentes I: Financial cost of osteoarthritis in France. The "COART" France study. Joint Bone Spine 2005, 72:567-570.

4. Hadler NM: Osteoarthritis as a public health problem. Clin Rheum Dis 1985, 11(2):175-185.

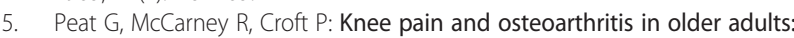
a review of community burden and current use of primary health care. Ann Rheum Dis 2001, 60:91-97

6. Simon LS: Osteoarthritis: a review. Clin Cornerstone 1999, 2:26-37.

7. @Felson DT: The epidemiology of osteoarthritis: prevalence and risk factors. In Osteoarthritic disorders. Edited by Kuettner KE, Goldberg CH. Rosemont (IL): American Academy of Orthopaedic Surgeons; 1995:13-24.

8. Hart FD: Pain in osteoarthrosis. Practitioner 1974, 212:244-250.

9. Kidd BL: Osteoarthritis and joint pain. Pain 2006, 123:6-9.

10. Dieppe PA, Lohmander LS: Pathogenesis and management of pain in osteoarthritis. Lancet 2005, 365:965-973.

11. Brandt KD, Dieppe P, Radin EL: Etiopathogenesis of osteoarthritis. Rheum Dis Clin North Am 2008, 34:531-559.

12. Jason J, MC D, Lisa W, Zongming L: Vasoactive intestinal peptide (VIP) is a modulator of joint pain in a rat model of osteoarthritis. Pain 2006 123:98-105.

13. Cerda-Reverter JM, Larhammar D: Neuropeptide $Y$ family of peptides: Structure, anatomical expression, function, and molecular evolution. Biochem Cell Biol 2000, 78:371-392.

14. Duggan AW, Hope PJ, Lang CW: Microinjection of neuropeptide Y into the superficial dorsal horn reduces stimulus-evoked release of immunoreactive substance $P$ in the anaesthetized cat. Neuroscience 1991, 44:733-740.

15. Munglani R, Hudspith MJ, Hunt SP, Hunt SP: The therapeutic potential of neuropeptide Y. Analgesic, anxiolytic and antihypertensive. Drugs 1996, 52(Hunt, S.P):371-389.

16. Silva AP, Cavadas $C$, Grouzmann E: Neuropeptide $Y$ and its receptors as potential therapeutic drug targets. Clin Chim Acta 2002, 326:3-25.

17. Pedrazzini T, Pralong F, Grouzmann E: Neuropeptide Y: The universal soldier. Cell Mol Life Sci 2003, 60:350-377.

18. Bedoui S, Kawamura N, Straub RH, Pabst R, Yamamura T, von Horsten S: Relevance of neuropeptide $\mathrm{Y}$ for the neuroimmune crosstalk. J Neuroimmunol 2003, 134:1-11.

19. Bedoui S, Miyake S, Lin Y, Miyamoto K, Oki S, Kawamura N, Beck-Sickinger A, von Horsten S, Yamamura T: Neuropeptide Y (NPY) suppresses experimental autoimmune encephalomyelitis: NPY1 receptor-specific inhibition of autoreactive Th1 responses in vivo. I Immunol 2003, 171:3451-3458.

20. Taiwo OB, Taylor BK: Antihyperalgesic effects of intrathecal neuropeptide Y during inflammation are mediated by Y1 receptors. Pain 2002, 96:353-363

21. Taylor BK, Dadia N, Yang CB, Krishnan S, Badr M: Peroxisome proliferatoractivated receptor agonists inhibit inflammatory edema and hyperalgesia. Inflammation 2002, 26:121-127.

22. Ma W, Bisby MA: Partial and complete sciatic nerve injuries induce similar increases of neuropeptide $Y$ and vasoactive intestinal peptide immunoreactivities in primary sensory neurons and their central projections. Neuroscience 1998, 86:1217-1234.

23. Ossipov MH, Zhang ET, Carvajal C, Gardell L, Quirion R, Dumont Y, Lai J, Porreca F: Selective mediation of nerve injury-induced tactile hypersensitivity by neuropeptide Y. J Neurosci 2002, 22:9858-9867.
24. Tatemoto K: Neuropeptide $\mathrm{Y}$ : complete amino acid sequence of the brain peptide. Proc Natl Acad Sci U S A 1982, 79(18):5485-5489.

25. Lundberg JM: Terenius L, H6kfelt T., Martling C.-R., Tatemoto, K., Mutt V., Polak J., Bloom S., Goldstein M. Neuropeptide Y (NPY)-like immunoreactivity in peripheral noradrenergic neurons and effects of NPY on sympathetic function. Acta Physiol Scand 1982, 116:477-480.

26. Ichikawa $\mathrm{H}$, Wakisaka S, Matsuo S, Akai M: Peptidergic innervation of the temporomandibular disk in the rat. Experientia 1989, 45:303-304.

27. Taylor BK, Abhyankar SS, Vo NT, Kriedt CL, Churi SB, Urban JH: Neuropeptide $\mathrm{Y}$ acts $\mathrm{Y} 1$ receptors in the rostral ventral medulla to inhibit neuropathic pain. Pain 2007, 131:83-95.

28. Ji RR, Zhang $X$, Wiesenfeld-Hallin Z, Hokfelt T: Expression of neuropeptide $\mathrm{Y}$ and neuropeptide $\mathrm{Y}(\mathrm{Y} 1)$ receptor $\mathrm{mRNA}$ in rat spinal cord and dorsal root ganglia following peripheral tissue inflammation. J Neurosci 1994, 14:6423-6434

29. Hokfelt T, Brumovsky P, Shi T, Pedrazzini T, Villar M: NPY and pain as seen from the histochemical side. Peptides 2007, 28:365-372.

30. Gibson SJ, Polak JM, Allen JM, Adrian TE, Kelly JS, Bloom SR: The distribution and origin of a novel brain peptide, neuropeptide $Y$, in the spinal cord of several mammals. J Comp Neurol 1984, 227:78-91.

31. Porreca F, Ossipov MH, Gebhart GF: Chronic pain and medullary descending facilitation. Trends Neurosci 2002, 25:319-325.

32. Ren $\mathrm{K}$, Dubner R: Descending modulation in persistent pain: An update. Pain 2002, 100:1-6.

33. Just S, Pawlak M, Heppelmann B: Responses of fine primary afferent nerve fibres innervating the rat knee joint to defined torque. J Neurosci Methods 2000, 103:157-162

34. Schaible HG, Schmidt RF: Responses of fine medial articular nerve afferents to passive movements of knee joints. J Neurophysiol 1983, 49:1118-1126.

35. Wagstaff S, Smith OV, Wood PH: Verbal pain descriptors used by patients with arthritis. Ann Rheum Dis 1985, 44:262-265.

36. Altman R, Asch E, Bloch D, Bole G, Borenstein D, Brandt K, Christy W, Cooke TD, Greenwald R, Hochberg M, Howell D, Kaplan D, Koopman W, Longley S II, Mankin H, McShane DJ, Medsger T Jr, Meenan R, Mikkelsen W, Moskowitz R, Murphy W, Rothschild B, Segal M, Sokoloff L, Wolfe F: Development of criteria for the classification and reporting of osteoarthritis. Arthritis Rheum 1986, 29:1039-1049.

37. Hideo Watanabe: Rihabiritēshon shinnyō hikkei. Tōkyō: Ishiyaku Shuppan; 1982.

38. Koshino T, Yoshida T, Ara Y, Saito I, Saito T: Fifteen to twenty-eight years' follow-up results of high tibial valgus osteotomy for osteoarthritic knee. Knee 2004, 11:439-444.

39. Selvon F: St. Clair, Carlos Higuera, Viktor Krebs, Nabil A. Tadross, Jerrod Dumpe, Wael K. Barsoum. Hip and Knee Arthroplasty in the Geriatric Population. Clin Geriatr Med 2006, 22:515-533.

40. Larsson J, Ekblom A, Henriksson K, Lundeberg T, Theodorsson E: Immunoreactive tachykinins, calcitonin gene-related peptide and neuropeptide $\mathrm{Y}$ in human synovial fluid from inflamed joints. Neurosci Lett 1989, 100:326-330

41. Larsson J, Ekblom A, Henriksson K, Lundeberg T, Theodorsson E: Concentration of substance $P$, neurokinin $A$, calcitonin gene-related peptide, neuropeptide $\mathrm{Y}$ and vasoactive intestinal polypeptide in synovial fluid from knee joints in patients suffering from rheumatoid arthritis. Scand I Rheumatol 1991, 20:326-335.

42. Lethbridge-Cejku M, Scott WW, Reichle R, Ettinger WH, Zonderman A, Costa $P$, Plato CC, Tobin JD, Hochberg MC: Association of radiographic features of osteoarthritis of the knee with knee pain: data from the Baltimore Longitudinal Study of Aging. Arthritis Care Res 1995, 8:182-188.

43. Dieppe PA: Relationship between symptoms and structural change in osteoarthritis. What are the important targets for osteoarthritis therapy? J Rheumatol Suppl 2004, 70:50-53.

44. Felson DT, Naimark A, Anderson J, Kazis L, Castelli W, Meenan RF: The prevalence of knee osteoarthritis in the elderly. The Framingham Osteoarthritis Study. Arthritis Rheum 1987, 30:914-918.

45. Hannan MT, Felson DT, Pincus T: Analysis of the discordance between radiographic changes and knee pain in osteoarthritis of the knee. J Rheumatol 2000, 27:1513-1517.

46. Claessens AA, Schouten JS, van den Ouweland FA, Valkenburg HA: Do clinical findings associate with radiographic osteoarthritis of the knee? Ann Rheum Dis 1990, 49:771-774. 
47. Bedson J, Croft P: The discordance between clinical and radiographic knee osteoarthritis: a systematic search and summary of the literature. BMC Musculoskelet Disord 2008, 9:116.

48. Scott DT, Lam FY, Ferrell WR: Acute joint inflammation mechanisms and mediators. Gen Pharmacol 1994, 7:1285-1296.

49. Schaible HG, Schmidt RF: Effects of an experimental arthritis on the sensory properties of fine articular afferent units. J Neurophysiol 1985, 54:1109-1122

50. Schaible H, Grubb BD: Afferent and spinal mechanisms of joint pain. Pain 1993, 55:5-54

51. Levine JD, Dardick SJ, Roizen MF, Helms C, Basbaum A: I..Contribution of sensory afferents and sympathetic efferent to joint injury in experimental arthritis. J Neurosci 1986, 6:3423-3429.

52. Woolf $\mathrm{CJ}$, Salter MW: Neuronal plascity: increasing the gain in pain. Science 2000, 288:1765-1768.

53. Ewald DA, Sternweis PC, Miller RJ: Guanine nucleotidebinding protein Go-induced coupling of neuropeptide $\mathrm{Y}$ receptors to $\mathrm{Ca}++$ channels in sensory neurons. Proc Natl Acad Sci U S A 1988, 85:3633-3637.

54. Walker MW, Ewald DA, Perney TM, Miller RJ: Neuropeptide Y modulates neurotransmitter release and $\mathrm{Ca}++$ currents in rat sensory neurons. J Neurosci 1988, 8:2438-2446.

55. Proudfit HK: Pharmacologic evidence for the modulation of nociception by noradrenergic neurons. In Pharmacologic Evidence for the Modulation of Nociception by Noradrenergic Neurons, Progress in Brain Research, Vol. 77. Edited by Fields HL, Besson JM. Amsterdam: Elsevier; 1988:357-370.

56. Holets VR, Hokfelt T, Rokaeus A, Terenius L, Goldstein M: Locus coeruleus neurons in the rat containing neuropeptide $Y$, tyrosine hydroxylase or galanin and their efferent projections to the spinal cord, cerebral cortex and hypothalamus. Neuroscience 1988, 24:893-906.

57. Sawchenko PE, Swanson LW, Grzanna R, Howe PR, Howe PR C, Bloom SR, Polak JM: Colocalization of neuropeptide $Y$ immunoreactivity in brainstem catecholaminergic neurons that projects to the paraventricular nucleus of the hypothalamus. J Comp Neurol 1985, 241:138-153.

58. Illes $\mathrm{P}$, Regenold JT: Interaction between neuropeptide $\mathrm{Y}$ and noradrenaline on central catecholamine neurons. Nature 1990, 344:62-63.

doi:10.1186/1471-2474-15-319

Cite this article as: Wang et al:: Levels of neuropeptide $Y$ in synovial

fluid relate to pain in patients with knee osteoarthritis. BMC

Musculoskeletal Disorders 2014 15:319.

\section{Submit your next manuscript to BioMed Central and take full advantage of:}

- Convenient online submission

- Thorough peer review

- No space constraints or color figure charges

- Immediate publication on acceptance

- Inclusion in PubMed, CAS, Scopus and Google Scholar

- Research which is freely available for redistribution 